\title{
Ativismo judicial, judicialização da política e politização da justiça no estado de direito contemporâneo
}

Guilherme Sandoval Góes ${ }^{1}$

\section{Resumo}

A "viragem neoconstitucionalista do direito" implicou mudanças paradigmáticas na teoria da eficácia dos direitos fundamentais, na medida em que engendrou um novo arquétipo exegético voltado para a força normativa da Constituição, cuja base fundante é o reconhecimento dos princípios como normas jurídicas. É nesse sentido que desponta o ativismo judicial, daí a pretensão do presente artigo de analisar tal fenômeno, comparando-o com os conceitos de judicialização da política e politização da justiça, de modo a poder traçar os limites exegéticos do protagonismo judicial no âmbito do Estado Democrático de Direito contemporâneo. Seu grande desafio é propor um equilíbrio entre a liberdade de conformação do legislador democrático e a efetividade dos direitos fundamentais.

Palavras-chave: Ativismo judicial; Judicialização da política; Politização da justiça.

\begin{abstract}
The "neoconstitutionalist turn of law" implied paradigmatic changes in the theory of the effectiveness of fundamental rights, as it engendered a new exegetical archetype aimed at the normative force of the Constitution, whose founding basis is the recognition of principles as legal norms. It is in this sense that judicial activism emerges, hence the intention of this article to analyze this phenomenon, comparing it with the concepts of judicialization of politics and politicization of justice, in order to draw the exegetical limits of judicial protagonism within the scope of the Contemporary Rule of Law. Its great challenge is to propose a balance between the freedom of conformation of the democratic legislator and the effectiveness of fundamental rights.
\end{abstract}

Keywords: Judicial activism, Judicialization of politics; Politicization of justice.

\footnotetext{
${ }^{1}$ Pós-doutor em Geopolítica, Cultura e Direito pela Universidade da Força Aérea (UNIFA). Doutor e Mestre em Direito pela Universidade do Estado do Rio de Janeiro (UERJ). Professor Emérito da Escola de Comando e EstadoMaior do Exército (ECEME). Membro do Fórum Permanente de Direitos Humanos e Professor de Direito da Escola da Magistratura do Estado do Rio de Janeiro (EMERJ). Professor de Direito Constitucional e Teoria do Estado da Universidade Cândido Mendes (UCAM). Diplomado pelo "Naval War College" dos Estados Unidos da América (Newport-Rhode Island, USA). E-mail: guilherme.sandoval@terra.com.br.
} 


\section{INTRODUÇÃO TEMÁTICA}

O surgimento do neoconstitucionalismo trouxe no seu bojo um novo modelo de interpretação constitucional, cujo eixo epistemológico aponta para o protagonismo do Poder Judiciário, transformando-o em legislador positivo, nas hipóteses de omissão inconstitucional do Poder Competente.

Também denominado de novo constitucionalismo, o paradigma neoconstitucionalista encontra seu alicerce teorético no pós-positivismo ou principialismo, que abarca, como bem destaca Luís Roberto Barroso, dentre outros, a atribuição de normatividade aos princípios, a reabilitação da argumentação jurídica e o desenvolvimento de uma teoria dos direitos fundamentais edificada sob a ideia de dignidade da pessoa humana. Nesse ambiente, promovese uma reaproximação entre o Direito e a Ética (Prefácio, BARCELLOS, 2005).

Isto significa dizer que o direito pátrio incorporou na sua equação epistemológica a racionalidade retórico-argumentativa de juízes e tribunais, viabilizando dessarte o "giro póspositivista" da reconstrução neoconstitucionalista do direito, provocado por sua vez pelo "giro pragmático da filosofia da linguagem”, especialmente após a obra de Wittgenstein II (1996).

Nesse sentido, precisa a visão de Écio Oto Ramos Duarte:

Para esse intento, é necessário um escorço das teorias básicas apresentadas pela Filosofia da Linguagem, especialmente as elaboradas por autores como Wittgenstein, Searle e Austin. Além dessas construções teóricas estruturarem os pressupostos de uma teoria filosófica da linguagem capaz de imprimir a razão linguística na reflexão dos fenômenos jurídicos, é salutar frisar que o próprio giro pragmático ocorrido na Filosofia da Linguagem provocará, por sua vez, um "giro epistemológico" no âmbito das investigações metodológico-jurídicas que, agora, desde um paradigma de racionalidade discursiva, deverá refletir-se em um novo condicionamento à elaboração da própria Teoria do Direito (DUARTE, 2004, p. 35) (grifo nosso).

Assim sendo, insista-se, por fundamental, nesta visão de que o giro pós-positivista do novo constitucionalismo entende que a efetividade (eficácia social) de uma determinada norma constitucional não pode ser aferida apenas pelo seu "texto escrito" posto pelo legislador democrático, mas, deve também levar em consideração a argumentação jurídica posta pelo magistrado diante do caso decidendo.

Eis aqui a base fundante do ativismo judicial, qual seja a criação de direito pelo Poder Judiciário nos casos de síndrome da inefetividade da Constituição. Isto significa dizer que o ativismo judicial é fundamental para a efetividade das normas constitucionais, notadamente naquelas situações onde impera a mora inconstitucional do legislador democrático na regulamentação dos direitos fundamentais submetidos a uma reserva legal, simples ou qualificada. 
No entanto, há que se reconhecer, por outro lado, que o ativismo judicial pode ser feito para o bem ou para o mal da democracia.

A criação do direito pelo Poder Judiciário no lugar do legislador democrático será benigna (ativismo judicial proporcional) quando consoante o sentimento constitucional de justiça e quando feita com a finalidade de superar a síndrome da inefetividade das normas constitucionais.

Com efeito, compreende-se melhor o fenômeno do ativismo judicial proporcional quando circunscrito à resolução dos conflitos normativos de mesma dignidade constitucional (casos de ponderação de normas constitucionais dentro de um mesmo caso concreto, usando a tríade subprincipial da proporcionalidade), sem o qual a Constituição perde a sua força normativa, tão arduamente conquistada ao longo da evolução civilizatória do direito.

O grande diferencial do ativismo judicial proporcional é a sua legitimação democrática que advém do respeito ao princípio da separação de poderes e da busca pela efetividade das normas constitucionais, ainda que relativa ao seu conteúdo jurídico mínimo, isto é, seu núcleo essencial intangível. Sem invadir desproporcionalmente o espaço discricionário do legislador democrático, o ativismo judicial proporcional garante o núcleo essencial de toda e qualquer norma constitucional, independentemente de lei regulamentadora superveniente.

Esse critério material reconduzir-se-ia, pois, a uma tentativa de salvaguardar um núcleo essencial de matérias com indiscutível dignidade constitucional e a consequente superioridade sobre as leis ordinárias (CANOTILHO, 1993, p. 71). No dizer do autor:

Todavia - e esta é a segunda ideia fundamental -, a introdução da ideia de mutabilidade de conteúdos não significa que não se deva procurar, reflexivamente, um mínimo de conteúdo constitucional, isto é, uma determinada identidade constitucional capaz de corresponder às "expectativas de prestação" que os homens anseiam ver num contrato fundacional, designadamente nos planos da segurança individual e de orientação colectiva (CANOTILHO, 1993, p. 106-107).

Em consequência, fica claro que o fenômeno do ativismo judicial não pode extrapolar os limites impostos pelo núcleo intangível dos direitos constitucionais e, em especial, o conteúdo jurídico mínimo dos direitos fundamentais. Em termos simples, a criação de direito feita pelo magistrado na solução do caso concreto não pode estar desvinculada do núcleo essencial da norma constitucional.

Se isso ocorrer, estar-se-á diante de um ativismo judicial desproporcional (decisionismo judicial) violador da separação de poderes e do Estado Democrático de Direito. Com efeito, o giro neoconstitucionalista do direito visa a superar a síndrome da inefetividade das normas constitucionais, mas, no entanto, não admite o mero decisionismo 
judicial, aqui vislumbrado como a criação de direito desvinculada do sentimento constitucional de justiça e calcada na vontade política de juízes e tribunais.

Muito pior do que uma norma constitucional inconcretizada por falta de regulação, é uma norma constitucional concretizada pela mera vontade política de um juiz partidário, eivado de déficit democrático por não se submeter à aprovação popular.

É nesse diapasão que o fenômeno do ativismo judicial não pode ser confundido com o conceito de politização da justiça, que projeta exatamente essa distorção democrática de juízes e tribunais decidindo de acordo com a sua própria vontade política e não com a vontade do sentimento constitucional de justiça.

O fenômeno da politização da justiça agride frontalmente a separação dos poderes e o Estado Democrático de Direito. Trata-se da partidarização do Poder Judiciário, o que evidentemente distorce a democracia, uma vez que magistrados não podem decidir de acordo com suas preferências político-partidárias.

Nesse sentido, a politização indevida da justiça cria as condições de possibilidade do mero decisionismo judicial, ou seja, do ativismo judicial desproporcional ou maligno. Isto significa dizer que a decisão judicial não é um ato de vontade do juiz; não é um ato de poder que se atrela à pré-compreensão do magistrado.

Com efeito, a resposta constitucionalmente adequada, que idealmente sempre deve ser a decisão final de mérito de juízes e tribunais, não pode ficar submetida a critérios pessoais, pré-conceitos ou escolhas político-partidárias, daí a visão de Lenio Streck quando afirma que "é na linguagem que se dá o sentido (e não na consciência de si do pensamento pensante" (2010, p. 14), arrematando mais adiante que o "direito não é aquilo que o judiciário diz que é" (2010, p. 106).

Da mesma forma, os fenômenos do ativismo judicial e da politização da justiça também não podem ser confundidos com o conceito da judicialização da política.

Com rigor, a judicialização da política não é ação volitiva do Poder Judiciário, escolha consciente de juízes e tribunais, ao revés, em atenção ao princípio da inafastabilidade do controle jurisdicional, o Poder Judiciário é obrigado a julgar todas as ações que lhes são submetidas pelos legitimados ad causam. Daí decorre que o fenômeno da judicialização da política não é culpa do Estado-Juiz, mas, sim, fruto da própria Constituição e do nosso sistema de controle de constitucionalidade. ${ }^{2}$

\footnotetext{
${ }^{2}$ Assim sendo, judicialização da política significa, em essência, que questões políticas fundamentais do Estado estão sendo decididas pelo Poder Judiciário, e, não, pelo Congresso Nacional e pelo Presidente da República, decisores democráticos da vida política nacional. Tais questões são levadas ao Poder Judiciário, seja pelos legitimados do artigo 103 da Constituição em sede concentrada, seja pelo cidadão comum a partir de um caso concreto qualquer em sede de controle difuso (GÓES; MELLO, 2018, p. 577).
} 
Não é culpa do STF o recebimento de uma ação direta de inconstitucionalidade impetrada por partido político com representação no Congresso Nacional. A judicialização dessa política pública não decorreu de uma opção do STF.

É nesse sentido que o presente artigo pretende examinar detalhadamente o fenômeno do ativismo judicial que não pode ser confundido, nem com a judicialização da política e nem com o mero decisionismo judicial e, muito menos, ainda, com a politização da justiça. Enfim é este o espectro temático do presente artigo.

\section{O ESTADO DE DIREITO ENTRE O ATIVISMO DO JUIZ NEOCONSTITUCIONAL E O DECISIONISMO DO JUIZ SOLIPSISTA}

Como já amplamente visto, o neoconstitucionalismo brasileiro não ficou apartado da viragem hermenêutica, que aproximou o direito de outros fluxos epistemológicos, e.g., filosofia, ética, sociologia, antropologia, ciência política etc.

De fato, há que se reconhecer que o novo constitucionalismo de inspiração póspositivista se caracteriza por certo protagonismo de juízes e tribunais em detrimento da autonomia normativa do legislador democrático, o que evidentemente pode acarretar riscos de implantação de um Estado Judicial de Direito, aqui vislumbrado como a distorção do Estado de Direito por predominância cêntrica do Poder Judiciário.

Em consequência disso e, de certa maneira, em perspectiva metacrítica ao positivismo jurídico, já se percebe grande reação doutrinária e jurisprudencial ao neoconstitucionalismo. Assim, após uma fase inicial de grande entusiasmo com a reconstrução neoconstitucionalista do direito, é certo dizer que se avoluma pensamento contrário ao protagonismo do Poder Judiciário em relação aos demais Poderes.

Acusa-se o neoconstitucionalismo de que de "neo" não teria nada, pois, a cada dia que passa aumenta o poder discricionário de juízes e tribunais, justificando a designação de Estado Judicial de Direito, violador da separação de poderes. Nesse sentido, o direito não pode ser aquilo que juízes e tribunais dizem que é.

Ao contrário, como bem destaca Lenio Streck, o direito é tudo aquilo que:

a lei manda, mas também o que os juízes interpretam, os advogados argumentam, as
partes declaram, os teóricos produzem, os legisladores sancionam e os doutrinadores
criticam. É, enfim, um discurso constitutivo, uma vez que designa/atribui significados
a fatos e palavras" (STRECK, 2009, p. 248).

Em essência, a crítica ao neoconstitucionalismo destaca sua incapacidade exegética de neutralizar a discricionariedade do juiz pós-positivista, acusando-o de ser mais solipsista do que o próprio juiz positivista. 
Ou seja, o neoconstitucionalismo pós-positivista seria mero modismo intelectual, desprovido de cientificidade e violador da separação de poderes e do Estado Democrático de Direito. Ainda na esteira acadêmica de Lenio Streck tem-se que:

\begin{abstract}
Se se quiser, poder-se-á dizer que a discricionariedade que combato - e nesse sentido me aproximo da posição de C. Neves - é aquela decorrente do esquema sujeito-objeto, da consciência de si do pensamento pensante, enfim, da subjetividade assujeitadora de um sujeito que se considera "proprietário dos sentidos (abstratos) do Direito" e que nada "deixa" para a faticidade. Permaneço, destarte, fiel à tese assumida de há muito, de maneira a enfatizar e a reprimir com veemência - a começar pela nomenclatura a possibilidade de o discricionário (repita-se, de aceitabilidade conceitual cogitável uma vez contextualizada a discricionariedade naqueles limites traçados por Castanheira Neves) revestir-se de arbitrário (STRECK, 2009, p. 422).
\end{abstract}

É nesse sentido que desponta a urgência de uma nova estratégia hermenêutica de interpretação constitucional, que seja capaz de impor maior cientificidade aos paradigmas de racionalidade discursiva (dianoética), sem adentrar ao campo do mero decisionismo judicial do juiz solipsista do positivismo jurídico.

Com efeito, o grande desafio do hodierno Estado Democrático de Direito é afastar a possibilidade de implantação de um "Estado Judicial de Direito", no qual se constata o mero decisionismo judicial focado na pré-compreensão do magistrado. Para tanto, urge seguir a trilha da Constituição em sentido normativo de Konrad Hesse, na qual se busca ir além da legalidade estrita, porém sem desprezar o direito posto.

É o que Karl Larenz denomina de "direto extra legem et intra jus" (1968, p. 502), ou seja, o direito que supera a letra da lei, mas, que, no entanto, permanece subordinado à ordem jurídica como um todo. Portanto, sem descambar para o decisionismo solipsista do magistrado positivista, a decisão final do juiz neoconstitucionalista não será necessariamente o resultado de uma operação exegética de subsunção silogística (direto extra legem), mas, também, de um processo de ponderação de valores que leva em consideração todos os princípios existentes na ordem constitucional (direto intra jus).

Com a devida agudeza de espírito, note-se que a teoria neoconstitucional faz uso do sentimento constitucional de justiça para superar o positivismo jurídico, sem, contudo, abandonar as conquistas desse mesmo positivismo. ${ }^{3}$

Ou seja, o juiz neoconstitucional não pode ponderar valores, quando for possível subsumir, da mesma forma que não pode apenas subsumir quando for necessário ponderar, notadamente nos denominados casos difíceis (hard cases), que nascem de uma colisão de normas de mesma hierarquia constitucional.

\footnotetext{
${ }^{3}$ É necessário, portanto, destacar que a nova interpretação constitucional não se coaduna com o mero decisionismo judicial do juiz solipsista, no qual a criação jurisprudencial do Direito é feita a talante do magistrado, totalmente desconectado do sentimento constitucional de justiça. (GÓES; MELLO, 2018, p. 124-125).
} 
Em consequência, há que se reconhecer que a resposta constitucionalmente adequada em determinados casos concretos (easy cases) será obtida por intermédio de uma simples operação exegética de subsunção silogística do binômio fato-norma, sem a necessidade de se recorrer à técnica de ponderação de valores.

Não há nenhuma hierarquia entre a técnica da ponderação de princípios constitucionais e a subsunção silogística das regras constitucionais. O que é superado no positivismo jurídico é a crença na completude do direito, que não leva em consideração o Estado de Direito em sua acepção substancialista, na qual a ordem jurídica projeta um conjunto de valores axiológicos que são compartilhados com a comunidade aberta de intérpretes da Constituição, tal qual vislumbrada por Peter Häberle (1997).

Fácil é perceber, portanto, a inexorável relevância do paradigma neoconstitucional no direito brasileiro, que é axiologicamente fragmentado, vale dizer formado por um constitucionalismo compromissório que, a um só tempo, busca harmonizar valores fundantes da democracia liberal e da social democracia.

É por isso que a aplicação mecânica da lei, sem ativismo judicial, torna desnutrido o processo de interpretação constitucional, na medida em que a operação exegética fica desprovida do jogo concertado dos princípios constitucionais, principal instrumento da reaproximação entre a ética e o direito.

No entanto, esse jogo no contexto global dos princípios constitucionais deve ser jogado de modo rigorosamente científico, cabendo à sociedade aberta de intérpretes da Constituição aferir a legitimidade democrática da sentença judicial aditiva advinda da ponderação de valores feita pelo magistrado no caso decidendo. Em outros termos, a resposta constitucionalmente adequada que resultou dessa ponderação de valores não admite o ativismo do juiz solipsista, que decidiu de acordo com a sua pré-compreensão e somente depois foi buscar a argumentação jurídica que justifica sua decisão judicial.

Em suma, a legitimidade democrática da sentença judicial aditiva (ativismo jurídico) do juiz neoconstitucionalista vem do rigor científico-metodológico usado na sua obtenção, bem como da sua aceitabilidade pela sociedade aberta de intérpretes da Constituição de Peter Häberle.

As convicções políticas do magistrado não têm o condão de suplantar as do legislador e/ou do administrador democráticos. Ou seja, o juiz neoconstitucionalista não é livre para impor sua própria vontade política (politização da justiça); não é soberano para decidir conforme sua própria pré-compreensão e/ou consciência (decisionismo solipsista), ao revés, é obrigado a convencer o Auditório Universal de Perelman (comunidade aberta de intérpretes) de que sua norma-decisão está consoante com o sentimento constitucional de justiça, que, por sua vez, 
guarda os valores éticos da sociedade como um todo e, especialmente, o princípio da dignidade da pessoa humana.

De tudo se vê, portanto, que a sentença judicial aditiva baseada na pré-compreensão do juiz solipsista é criação antidemocrática de direito que não se coaduna com a Constituição de 1988.

\section{A LEGITIMIDADE DEMOCRÁTICA E $O$ O PODER CONTRAMAJORITÁRIO DE JUÍZES E TRIBUNAIS NO ESTADO DE DIREITO HODIERNO}

O juiz do século XXI, sob a égide do neoconstitucionalismo, deve aplicar cientificamente a dogmática pós-positivista para conceber sua norma-decisão quando já considerada no plano concreto de significação (plano all things considered). ${ }^{4}$

É nesse sentido que desponta a face positiva do ativismo judicial, qual seja: a criação jurisprudencial do direito é feita de forma científica, levando-se em consideração todos os elementos fáticos (fatos que portam juridicidade), bem como todos os conflitos de direitos constitucionais existentes no caso concreto.

Com isso, o Poder Judiciário passa a satisfazer determinadas demandas da sociedade que até então não eram atendidas pelo Estado-legislador. Além disso, há que reconhecer que não haverá democracia efetiva sem atividade juscriativa do Poder Judiciário, sanando a omissão inconstitucional do legislador democrático.

Já o aspecto negativo do ativismo judicial reside na possibilidade de violação da separação de poderes, criando dessarte grandes riscos de implantação do Estado Judicial de Direito (Distorção do Estado de Direito pela supremacia do Judiciário em relação ao Executivo e ao Legislativo).

Essa temática é complexa, na medida em que envolve um edifício epistemológico muito amplo que é construído a partir de diferentes abordagens conceituais contraditórias entre si, tais como a dificuldade contramajoritária do Poder Judiciário (BICKEL, 1986), o ativismo judicial democrático (proporcional), o decisionismo solipsista antidemocrático (desproporcional), a judicialização da política e a politização da justiça.

É dentro desse contexto conceitualmente multinucleado que desponta a questão da legitimidade democrática de o Poder Judiciário para criar direito novo no lugar do Legislativo. Com efeito, como já visto alhures, a flexibilidade de o Poder Judiciário legislar positivamente tem limites, sejam limites orçamentários do Estado para atender a todas as

\footnotetext{
${ }^{4}$ No pensamento de Humberto Ávila: "é preciso distinguir o plano preliminar de análise abstrata das normas, comumente chamado de plano prima facie de significação, do plano conclusivo de análise concreta das normas, comumente denominado all things considered de significação" (ÁVILA, 2004, p. 57).
} 
demandas da sociedade (conceito de reserva do possível), sejam limites epistêmicos (juízes não conhecem todas as áreas do conhecimento humano), sejam limites hermenêuticos (as decisões judiciais devem seguir rigorosos métodos científicos previamente concebidos).

Além disso, a formulação de políticas públicas é escolha dramática entre opões que, muitas vezes, são diametralmente opostas, reforçando assim a visão de que tal tarefa deve ser colocada nas mãos do legislador democrático.

É por tudo isso que é importante examinar as conexões entre os fenômenos do ativismo judicial, da judicialização da política e da politização da justiça, que, ainda, trazem no seu entorno científico os conceitos de decisionismo solipsista e dificuldade contramajoritária do Poder Judiciário.

Assim, comparando os conceitos de ativismo judicial e judicialização da política, Luis Roberto Barroso (2009) destaca que:

\begin{abstract}
a judicialização e o ativismo judicial são primos. Vêm, portanto, da mesma família, frequentam os mesmos lugares, mas não têm as mesmas origens. Não são gerados, a rigor, pelas mesmas causas imediatas. A judicialização, no contexto brasileiro, é um fato, uma circunstância que decorre do modelo constitucional que se adotou, e não um exercício deliberado de vontade política (...) Já o ativismo judicial é uma atitude, a escolha de um modo específico e proativo de interpretar a Constituição, expandindo o seu sentido e alcance. Normalmente ele se instala em situações de retração do Poder Legislativo, de um certo descolamento entre a classe política e a sociedade civil, impedindo que as demandas sociais sejam atendidas de maneira efetiva.
\end{abstract}

De tudo se vê, por conseguinte, que o ativismo judicial não se confunde com a judicialização da política, muito embora estejam quase que umbilicalmente atrelados. Normalmente, o ativismo judicial (juiz concretizando ou revisando determinadas políticas públicas do Legislativo, por exemplo) ocorre a partir da judicialização de uma questão política (políticas públicas feitas pelo Congresso Nacional são levadas ao STF pelo próprio Legislativo em sede concentrada de controle de constitucionalidade).

Por sua vez, a ideia de politização da justiça está associada a uma participação partidária mais intensa de Juízes, Desembargadores e Ministros, que se manifesta por meio de decisões judiciais diferentes de acordo com a cor partidária de réus ou de iniciativas públicas. A interpretação da Constituição fica a mercê dessa tendência partidária, o que evidentemente fere de morte a própria democracia.

Ademais, é importante constatar que é muito difícil neutralizar a politização da justiça, mormente no âmbito da Suprema Corte. Ora um verdadeiro Estado Democrático de Direito não pode admitir que as convicções políticas do magistrado, eivadas de déficit democrático em virtude da sua dificuldade contramajoritária, tal qual formulada por Bickel (1986), possam suplantar as vontades políticas do legislador democrático (GÓES; MELLO, 2021, p. 457). 
Com rigor, é o fenômeno da judicialização da política que cria a interface entre o mundo do ativismo solipsista antidemocrático e o mundo da politização da justiça, que passam, então a caminhar juntos e interligados. Aqui a criação de direito feita por juízes e tribunais é totalmente desvinculada da Constituição e do seu ideal axiológico de justiça social. Não se pode confundir o ativismo judicial proporcional ou benigno ou democrático com o mero decisionismo judicial solipsista antidemocrático, deslocado do sentimento constitucional de justiça, da democracia e da cientificidade do direito.

No entanto, é o mesmo fenômeno da judicialização da política que cria a interface entre o mundo do ativismo democrático proporcional e o mundo da realização do sentimento constitucional de justiça, da democracia e da dignidade da pessoa humana, que passam, então a caminhar juntos e interligados. ${ }^{5}$

É por isso que se pode afirmar que o trinômio "ativismo-judicialização-politização" está presente na maior parte das ações de controle concentrado de constitucionalidade, na medida em que o STF tem competência constitucional para decidir sobre a questão política que lhe foi submetida.

Infelizmente, é possível identificar a tendência partidária de grande parte dos Ministros da Suprema Corte. Além disso, alguns membros do Poder Judiciário, muito embora não sejam agentes públicos eleitos pelo povo, querem exercer a plenitude do poder político do Judiciário.

Onde estaria, então, a legitimidade democrática de juízes e tribunais, seja para invalidar leis formuladas pelos detentores de mandato popular, seja para formular políticas públicas no seu lugar? ${ }^{6}$

A resposta a tal questionamento vem com a ideia-força de que a legitimidade democrática das decisões judiciais não é função apenas da racionalidade literal da letra da lei, mas, também, da racionalidade discursiva (retórico-argumentativa) apresentada pelo juiz durante o processo de concretização da Constituição. Nesse sentido, é importante compreender que o neoconstitucionalismo pós-positivista coloca em contato direto a decisão judicial e sua aceitabilidade pela comunidade aberta de intérpretes da Constituição, tal qual vislumbrada por Peter Häberle.

Ou seja, é a sociedade como um todo (auditório universal de Perelman) que legitima democraticamente a decisão dos magistrados, uma vez que todos interpretam a Constituição

\footnotetext{
${ }^{5}$ Nesse sentido, observe com atenção, a visão do Ministro Luís Roberto Barroso: Em uma cultura pós-positivista, o Direito se aproxima da Ética, tornando-se instrumento da legitimidade, da justiça e da realização da dignidade da pessoa humana. Poucas críticas são mais desqualificantes para uma decisão judicial do que a acusação de que é política e não jurídica. Não é possível ignorar, porém, que a linha divisória entre Direito e Política, que existe inegavelmente, nem sempre é nítida e certamente não é fixa (BARROSO, 2009).

${ }^{6}$ Como bem destaca o professor Luís Roberto Barroso: Evidentemente, Direito não é política no sentido de admitir escolhas livres, tendenciosas ou partidarizadas. O facciocismo é o grande inimigo do constitucionalismo. $\mathrm{O}$ banqueiro que doou para o partido do governo não pode ter um regime jurídico diferente do que não doou. A liberdade de expressão de quem pensa de acordo com a maioria não pode ser protegida de modo mais intenso do que a de quem esteja com a minoria. O ministro do tribunal superior, nomeado pelo Presidente Y, não pode ter a atitude a priori de nada decidir contra o interesse de quem o investiu no cargo (BARROSO, 2009).
} 
(sociedade aberta de intérpretes da Constituição de Häberle) e, não, somente, a Corte Suprema do País.

Quanto mais próxima da ética, da democracia, da dignidade da pessoa humana e do sentimento constitucional de justiça, maior será o grau de legitimidade/aceitabilidade da sentença judicial. No dizer de Barroso: a conservação e a promoção dos direitos fundamentais, mesmo contra a vontade das maiorias políticas, é uma condição de funcionamento do constitucionalismo democrático. Logo, a intervenção do Judiciário, nesses casos, sanando uma omissão legislativa ou invalidando uma lei inconstitucional, dá-se a favor e não contra a democracia. (BARROSO, 2009).

De tudo se vê, por conseguinte, que a legitimidade democrática das decisões judiciais aditivas (decisões que criam direito novo) advinda da sociedade aberta de intérpretes da Constituição mitiga de certa forma a chamada dificuldade contramajoritária do Poder Judiciário, atenuando assim seu déficit democrático na formulação de políticas públicas.

Em essência, até mesmo o ativismo judicial proporcional ou democrático deve ser feito com parcimônia em nome da democracia e da separação de poderes, já que o Poder Judiciário é um poder contramajoritário não atrelado ao voto popular.

Com efeito, é preciso compreender que o Poder Judiciário é, por natureza, um poder contramajoritário, ou seja, um poder público não eleito pelo povo, cuja interpretação deve ser feita de duas maneiras distintas, a saber:

a) a natureza contramajoritária do Poder Judiciário representa um óbice a ser vencido por juízes e tribunais na formulação de políticas públicas (ativismo judicial), uma vez que apresentam déficit democrático por não estarem submetidos ao voto popular;

b) o poder contramajoritário do Poder Judiciário é uma garantia de direitos fundamentais para o cidadão comum no campo penal, na medida em que juízes e tribunais não julgam para as multidões.

Em linhas gerais, o conceito de dificuldade contramajoritária do Poder Judiciário projeta a imagem de que, em regra, a vontade política dos representantes do povo, detentores de milhões de votos populares deve prevalecer sobre a vontade política de magistrados (selecionados por concurso público e até mesmo por nomeações de caráter político). Assim, somente em hipóteses excepcionais, os agentes públicos não eleitos do Poder Judiciário podem invadir o espaço discricionário do legislador democrático, substituindo-o na formulação de políticas públicas.

De outra banda, há que se reconhecer que o poder contramajoritário do Poder Judiciário representa uma garantia constitucional, seja dos direitos das minorias perante a vontade ou ditadura das maiorias, seja dos direitos de acusados previamente julgados pela opinião pública. Nesse 
sentido, exatamente por não estar atrelado à opinião pública, o Poder Judiciário pode fazer um julgamento justo, mesmo em contexto de forte manifestação popular contrária.

\section{CONCLUSÃO}

Este artigo procurou traçar linhas gerais acerca dos conceitos de ativismo judicial, judicialização da política e politização da justiça no âmbito do Estado Democrático de Direito. Para tanto, destacou, inicialmente, seus dois grandes pilares de sustentabilidade, quais sejam: o princípio da separação de poderes e a positivação de um catálogo de direitos fundamentais acima do próprio Estado.

Assim, em regra, ao juiz, não lhe é dado intrometer-se na esfera do processo democrático de formulação de políticas públicas. Isto porque tal invasão poderia significar uma violação à separação de poderes e, na sua esteira, uma violação ao Estado Democrático de Direito. Por outro lado, urge desenvolver uma nova estratégia hermenêutica capaz de fazer avançar a teoria dos direitos fundamentais e, em especial, a garantia de vida digna para todos.

Portanto, hodiernamente, o novo constitucionalismo democrático deve trilhar caminho progressista, que desloque para a centralidade do sistema jurídico a dignidade da pessoa humana como novo eixo hermenêutico-axiológico do Estado Democrático de Direito. Há que se reconhecer que a Constituição de 1988 traz no seu âmago um amplo conjunto de valores axiológicos que se contrapõem entre si, cabendo ao exegeta constitucional ponderar os valores em colisão sob a égide do sentimento constitucional de justiça, daí a importância do exercício da jurisdição constitucional (GÓES; MELLO, 2021, p. 20-21).

Como amplamente visto, a reconstrução neoconstitucionalista do direito valoriza a dimensão retórico-argumentativa das decisões judiciais. Ou seja, a nova interpretação constitucional não se limita ao texto da norma (direito imanente à lei feito pelo legislador), ao contrário, vai buscar no quadro global de princípios jurídicos a resposta constitucionalmente adequada.

É por tudo isso que foi importante examinar a diferença entre os conceitos de judicialização da política, ativismo judicial e politização da justiça, que, ainda, trazem no seu entorno científico os conceitos de decisionismo judicial solipsista e dificuldade contramajoritária do Poder Judiciário.

Como visto, por judicialização da política entende-se o fenômeno que ocorre em virtude da própria Constituição e do nosso sistema de controle de constitucionalidade, não pressupondo vontade própria de o Poder Judiciário invadir o espaço discricionário da formulação de políticas públicas. Ou seja, em nome do princípio da inafastabilidade do controle jurisdicional, é obrigação do juiz decidir a lide, acolhendo ou não a pretensão, subjetiva ou objetiva, que lhe foi submetida. 
Assim, a ideia de politização da justiça não se confunde com a judicialização da política, muito embora estejam quase que umbilicalmente atreladas. Nesse sentido, o fenômeno da politização da justiça é mais uma grande objeção ao Estado Democrático de Direito porque se trata da partidarização de magistrados, que, não podem decidir de acordo com suas preferências político-partidárias. Nesse sentido, juntamente com o mero decisionismo judicial, a politização indevida da justiça representa um grande risco para a legitimidade democrática do Poder Judiciário.

No decisionismo do juiz solipsista, o fator determinante para a interpretação constitucional não é a literalidade do texto posto pelo legislador democrático, mas, sim, a sua pré-compreensão. Ou seja, a decisão judicial se afasta da cientificidade do direito para se basear tão somente na pré-compreensão do magistrado, que decide de acordo com suas convicções e sensações pessoais e depois procura a argumentação jurídica que respaldará sua decisão já previamente tomada. $^{7}$

Já no seu sentido positivo, o ativismo judicial projeta a imagem da força normativa da Constituição, na qual o protagonismo do Judiciário é focado na concretização dos valores constitucionais e dos direitos fundamentais, nas hipóteses de omissão do legislador democrático. Assim, em tempos de reconstrução neoconstitucionalista do direito, a efetividade ou eficácia social dos princípios constitucionais se consolida progressivamente pelo ativismo judicial atrelado à harmonização entre o tex to da lei e o sentimento constitucional de justiça.

Enfim, sob os influxos da dogmática pós-positivista, é preciso impor limites exegéticos, epistêmicos e orçamentários ao ativismo judicial, na medida em que se cria um espaço dentro do qual o intérprete da Constituição vai reconhecer o poder discricionário do legislador democrático. Em determinadas situações fáticas, o juiz deve reconhecer sua inaptidão para criar direito, respeitando tais limites.

Destarte, o excesso de ativismo judicial de uma Corte Suprema pode representar um desserviço ao Estado Democrático de Direito porque faz com que um poder contramajoritário formule políticas públicas no lugar do legislador democrático.

\section{REFERÊNCIAS}

ÁVILA, Humberto. Teoria dos princípios: da definição à aplicação dos princípios jurídicos. Rio de janeiro: Malheiros, 2004.

\footnotetext{
${ }^{7}$ Como bem destaca o professor Luís Roberto Barroso: Evidentemente, Direito não é política no sentido de admitir escolhas livres, tendenciosas ou partidarizadas. O facciocismo é o grande inimigo do constitucionalismo. O banqueiro que doou para o partido do governo não pode ter um regime jurídico diferente do que não doou. A liberdade de expressão de quem pensa de acordo com a maioria não pode ser protegida de modo mais intenso do que a de quem esteja com a minoria. O ministro do tribunal superior, nomeado pelo Presidente Y, não pode ter a atitude a priori de nada decidir contra o interesse de quem o investiu no cargo. (BARROSO, 2009).
} 
BARCELLOS, Ana Paula de. Ponderação, racionalidade e atividade jurisdicional. Rio de Janeiro: Renovar, 2005.

BARROSO, Luis Roberto. Judicialização, ativismo judicial e legitimidade democrática. Revista Atualidades Jurídicas, Brasília-DF, n. 4, jan./fev. 2009. Disponível em: https://bibliotecadigital.tse.jus.br/xmlui/bitstream/handle/bdtse/5498/2009_barroso_judicializ acao_ativismo_judicial.pdf?sequence=1\&isAllowed=y. Acesso em: 15 nov. 2021.

BICKEL, Alexander M. The Least Dangerous Branch, $2^{\mathrm{a}}$ ed. New Haven and London: Yale University Press, 1986.

CANOTILHO, J. J. Gomes. Direito constitucional e teoria da Constituição. Coimbra: Almedina, 1993.

DUARTE, Écio Oto Ramos. Teoria do discurso \& correção normativa do direito: aproximação à metodologia discursiva do direito. São Paulo, Editora Landy, 2ª ed., 2004.

GÓES, Guilherme Sandoval; MELLO, C. M. Controle de constitucionalidade. $2^{\mathrm{a}}$ ed. Rio de Janeiro: Processo, 2021.

GÓES, Guilherme Sandoval; MELLO, C. M. Direito constitucional. Rio de Janeiro: Processo, 2018.

HÄBERLE, Peter. Hermenêutica constitucional. A sociedade aberta dos intérpretes da Constituição: contribuição para a interpretação pluralista e 'procedimental' da Constituição. Tradução de Gilmar Ferreira Mendes. Porto Alegre: Sergio Antonio Fabris Editor, 1997.

LARENZ, Karl. Metodologia da ciência do direito. Tradução de José Lamego. Lisboa: Fundação Gulbenkian, 1968.

PERELMAN, Chäim. Lógica Jurídica. Nova retórica. São Paulo, Martins Fontes, 1998.

STRECK, Lenio Luiz. Verdade e consenso. Constituição, hermenêutica e teorias discursivas. Da possibilidade à necessidade de respostas corretas em direito. $3^{\mathrm{a}}$ ed., rev, atual. Rio de Janeiro: Lumen Juris, 2009.

STRECK, Lenio Luiz. O que é isto: decido conforme minha consciência? Porto Alegre: Livraria do Advogado, 2010.

WITTGENSTEIN, Ludwig. Investigações Filosóficas. 2. edição. Petrópolis: Editora Vozes Ltda, 1996. 